\title{
UMA COMPREENSÃO DO CONTEMPORÂNEO A PARTIR DO DIÁLOGO COM O PENSAMENTO DE MARTIN HEIDEGGER
}

\author{
Ellen Fernanda Gomes da Silva ${ }^{1}$ \\ Universidade Católica de Pernambuco (UNICAP) \\ Carmem L. B T. Barreto ${ }^{2}$ \\ Universidade Católica de Pernambuco (UNICAP) \\ (iD) https://orcid.org/0000-0002-5532-039X
}

\begin{abstract}
RESUMO
O presente artigo objetiva apresentar uma compreensão crítica do tempo presente, que se pode chamar de contemporaneidade. Nessa direção, as reflexões sobre esse momento histórico priorizaram os questionamentos filosóficos de Heidegger. Para interpretação mais ampla do pensamento heideggeriano, foi abordada, rapidamente, as concepções existenciais de homem e de mundo trazidas em sua obra "Ser e tempo". Após essas considerações, a "Era da Técnica", marcada pelo esquecimento do ser, foi tomada enquanto foco de discussão. Por fim, ressalta-se a inquietação não com relação ao crescimento da técnica planetária, mas sim acerca do fato de o homem não compreender a dimensão e o sentido das transformações empreendidas por esta destinação; rejeitando, com isso, aquilo que tem de mais próprio, a condição de ser o único ser que reflete.
\end{abstract}

PALAVRAS-CHAVE: Contemporaneidade; Perspectiva fenomenológica existencial; Técnica moderna.

\section{AN UNDERSTANDING OF THE CONTEMPORANEITY BY DIALOGUING WITH MARTIN HEIDEGGER'S THINKING}

\footnotetext{
1 Psicóloga; mestre em Psicologia Clínica e doutoranda em Psicologia Clínica na Universidade Católica de Pernambuco (UNICAP), Pernambuco - Brasil. E.mail: ellenfernanda1@hotmail.com

${ }^{2}$ Psicóloga; doutora em Psicologia pela Universidade de São Paulo (USP), São Paulo Brasil. Coordenadora do Programa de Pós-Graduação em Psicologia Clínica da Universidade Católica de Pernambuco (UNICAP), Pernambuco - Brasil. Coordenadora do Laboratório de Psicologia Clínica Fenomenológica Existencial - LACLIFE. E.mail: carmemluciabarreto@ hotmail.com
} 


\begin{abstract}
:
This article presents a critical understanding of this time, which can be called contemporary. In this direction, the reflections on this historic moment prioritized the philosophical questioning of Heidegger. For broader interpretation of Heidegger's thought, was addressed quickly, the existential conceptions of man and the world brought in his "Being and Time". After these considerations, the "Age of Technique", marked by forgetfulness of being, was taken as the focus of discussion. Finally, we highlight the concern not with respect to the growth of planetary technique, but about the fact that man does not understand the magnitude and direction of the changes undertaken by this allocation; rejecting it, what is most itself, the condition of being the only being who reflects.
\end{abstract}

KEYWORDS: Contemporary; Perspective existential phenomenological; Modern technique.

\title{
Introdução
}

"Começos do Terceiro Milênio! Profusão
exuberante detecnologia, patamares científicos
inéditos, resultados econômicos estrondosos,
produção magnífica de bens de consumo. Olhando
só para as conquistas, tudo é superlativo!"
(CORTELLA)

A contemporaneidade tem se apresentando de maneira ambígua: de um lado as promessas de felicidade, beleza e liberdade relacionadas às descobertas científicas e tecnológicas; de outro um temor quanto ao futuro caracterizado por controle da vida social, pela multiplicação das guerras, intensificação da violência cotidiana e desertificação da natureza. Esse contexto, narrado por Duarte (2010), caracteriza a superficialidade que, comumente, vivemos diante do nosso próprio tempo e assinala a dinâmica de valorização da vida acompanhada por uma atitude de depreciação e descarte dessa mesma vida.

$\mathrm{Na}$ trilha compreensiva de crítica do presente, o diálogo com o pensamento de Heidegger pode contribuir para o questionamento dos humanismos tradicionais e voltar a colocar o problema filosófico que, segundo Giacoia (2013, p. 13), nos concerne: "o que estamos fazendo de nós mesmos, em um tempo em que só as mutações são permanentes". Seguindo tal direção, Giacoia alerta a urgência de pensar com Heidegger para interrogar o delírio de onipotência da contemporaneidade, assim como a escalada compulsiva da técnica instrumental, a qual pode nos impelir para

Uma compreensão do contemporâneo a partir do diálogo com o pensamento de Martin Heidegger - Ellen Fernanda Gomes da Silva; Carmem L. B T. Barreto 
uma expansão planetária da tecnologia em um tempo histórico arriscado à existência do humano.

Sob esse ângulo, Duarte (2010) aponta a importância do modo de pensar de Heidegger para favorecer a crítica à razão instrumental, ao afirmar que o mesmo buscou desconstruir as pretensões absolutistas da ciência moderna. Uma das consequências deste procedimento desconstrutivo foi a perda, por parte das ciências, de sua exclusividade, bem como da força sobre o existir humano. A partir de uma perspectiva não metafísica, Heidegger enfatizou os riscos do procedimento de objetivação intrínseco às ciências, ressaltando a possibilidade de levar à transformação da Terra em um lugar inabitável e a própria destruição do ser-homem.

Continuando no intuito de refletir o momento contemporâneo, mais uma vez recorremos à Heidegger, especificamente, ao modo como compreendeu o espírito do seu tempo ao distanciar-se dos holofotes e receber em pleno rosto o facho das trevas. O seu caminhar apresenta algumas linhas de força. Os escritos da primeira fase, considerada como "Fenomenologia Ontológica da Existência", volta-se para a superação da metafísica na busca de "desconstruir" as categorias e pressupostos originais. Encaminha esta tarefa em "Ser e tempo" (2012), retomando sempre a pergunta pelo sentido do ser.

Em um segundo momento, denominado por alguns autores de "Heidegger tardio", busca-se a história da verdade do ser, refletindo sobre a essência da técnica moderna. Nessa linha de força, almeja-se resgatar "o esquecimento do sentido do ser" operado pela história da metafísica, ao refletir o ser do ente na sua totalidade.

Atravessado por esses dois momentos de meditação, o pensamento de Heidegger contribui para pensar o mundo atual, com suas crises e dilemas, bem como oferece caminhos para vislumbrar um futuro problemático, marcado pela técnica e desenraizamento do homem contemporâneo.

\section{Contextualizando brevemente o contemporâneo}

"São tempos existencialmente dificeis estes que nos coube vivenciar".

A posição sustentada por uma longa tradição afirma que determinada pessoa é contemporânea quando está adequada às pretensões e ideais do tempo no qual foi dada a viver. A indicação citada por Agamben (2009, p. 59) segue na contramão de tal posicionamento, ao narrar: "a contemporaneidade, portanto, é uma singular relação com o próprio tempo, que adere a este e, ao mesmo tempo, dele toma distâncias".

Continuando nessa linha de pensamento, contemporâneo se refere ao homem que mantém fixo o olhar no seu tempo, para nele perceber a 
obscuridade e não as luzes. $\mathrm{O}$ escuro não se refere apenas a simples ausência de luminosidade; equivale a neutralizar as luzes provenientes da época para descobrir as íntimas trevas, as quais são inseparáveis daquelas luzes. Assim, ser contemporâneo é perceber no escuro uma luz que, dirigida a nós, simultaneamente, distancia-se infinitamente. É por isso que para Agambem (2009, p. 65), ser contemporâneo é uma questão de coragem, já que significa: "[...] ser capaz não apenas de manter fixo o olhar no escuro da época, mas também de perceber nesse escuro uma luz que, dirigida para nós, distancia-se infinitamente de nós".

Considerando tais reflexões, Agamben (2009) assinala a moda como um exemplo esclarecedor desta temática. Segundo ele, a temporalidade da moda tem um caráter inapreensível: quando pronunciamos que estamos na moda o estilista concebe o traço definitivo do "agora" e do "ultrapassado" das vestes. Essa perspectiva reflete a dimensão episódica, fragmentada da existência atual. Num mundo assim, os estilos e preferências podem ser adotados e, simultaneamente, descartados como uma mudança de costume.

A contemporaneidade também se inscreve no presente com as assinaturas do arcaico, liga-se a esse tempo sem estar fixado nele e o modifica em uma intersecção de tempo múltiplos: "é como se aquela invisível luz, que é o escuro do presente, projetasse a sua sombra sobre o passado, e este, tocado por esse facho de sombra, adquirisse a capacidade de responder às trevas do agora" (AGAMBEN, 2009, p. 72). A divisão do presente em "não mais" e "ainda não" aponta para irrupção do passado e do futuro, do fluxo contínuo e simultâneo entre vida e morte.

Trazendo tais reflexões para o campo da existência humana, encontra-se a compreensão laica de contemporaneidade marcada pelo privilégio da individualidade em detrimento das relações de alteridade. Nesse contexto, os relacionamentos seguem a lógica do prazer contínuo e da diversão, sendo o outro descartado, ao surgir algum impasse ou ameaça de sofrimento. Estão marcados pelo tempo da vivência, analisado por Benjamin (1984) como o tempo do presente a requisitar uma reação, levando o homem de uma experiência a outra, não se deixando penetrar pelos acontecimentos. O tempo da vivência, considerado pelo autor citado, como infernal, levaria o homem a nunca terminar seus projetos, estando sempre a começar de novo e do princípio. A ideia reguladora desse tempo é a do jogo, no qual a cada partida todas as anteriores são anuladas, representando, desta forma, o tempo do trabalho operário nas linhas de montagem.

Caminhando também pela Sociologia, na tentativa de compreender o nosso tempo, recorremos a Bauman (2011) ao ajudar a pensar algumas formas de integração humana, quais sejam: móveis, àquelas da rua movimentada ou do Shopping Center, de proximidade momentânea e separação instantânea; as estacionárias unem diversos estranhos num vagão de trem, os quais sabem que provavelmente não se encontrarão novamente; as moderadas configuram uma matriz de encontros normalmente regrados, 
estritos e breves; já as manifestas, são de uma marcha de protesto cuja finalidade é junção com um grande grupo.

Em outros termos, Baumam (2011) sinaliza que, a despeito dos modos, os encontros comumente são fragmentados e episódicos, como se fossem uma entidade encerrada em si mesma, despida de uma história passada e um futuro. Nesse ínterim, "tendem a ser inconsequentes no sentido de não deixar um legado durável de direitos e/ou obrigações mútuos em seu rastro" (BAUMAM, 2011, p. 75). Partindo da suposição da agilidade do "jogo da vida", bem como da mutabilidade de suas "regras", a durabilidade das relações não é algo comum, não investindo no comprometimento. $\mathrm{O}$ andarilho, movido pelo pavor de estar preso ou fixo, oferece a metáfora para a estratégia atual; ele vive na companhia de superfícies, um nato colecionador de prazeres e sensações.

Após breves considerações filosóficas e sociológicas acerca da contemporaneidade, a seguir, será apresentado um possível diálogo do momento contemporâneo à luz do pensamento heideggeriano. Entretanto, para uma compreensão mais abrangente e preparação para as discussões seguintes, antes, serão abordadas as concepções de homem e de mundo trazidas em sua "Analítica Existencial".

\section{Fenomenologia existencial heideggeriana}

Por considerar a importância do pensamento de Heidegger, escolhido como marco de referência para as reflexões desenvolvidas, optou-se por fazer uma apresentação de suas reflexões, orientada por pontos de realce direcionados para o modo como compreende o homem e o mundo. Dado o recorte proposto nessa apresentação, alguns aspectos do pensamento heideggeriano serão apenas sinalizados ou não abordados, obedecendo ao critério de apoiar as reflexões vinculadas à temática a ser estudada. Tal escolha mostra-se oportuna visto a complexidade e expansão da obra de Heidegger.

As reflexões filosóficas heideggerianas consistem em pensar o problema do ser, questão esquecida pela metafísica. Nesta direção, Heidegger nos faz um convite a outros modos de pensar, na tentativa de superar o pensamento representacional, pragmático e tecnológico.

A Ontologia Fundamental heideggeriana expõe que a existência ( $E k$ sistencia) jamais é substancializada, visto o espaço sempre em fluxo temporal no qual a mesma se constitui. A partir do pensamento de Heidegger (2012) o Dasein homem é compreendido como ente que habita o aí, na abertura $(D a)$, onde compreende o ser das coisas (sein) e estabelece condições de possibilidade para o homem ser propriamente o que "é".

Para demarcar seu modo de pensar, Heidegger refere-se ao Dasein como existir no devir temporal, ente cuja essência é o existir enquanto projeto. Nessa perspectiva, não há essência humana, do contrário, apresenta-se

Uma compreensão do contemporâneo a partir do diálogo com o pensamento de Martin Heidegger - Ellen Fernanda Gomes da Silva; Carmem L. B T. Barreto 
como poder-ser, condição tida como determinação mais própria da existência. Enfatizando a historicidade da existência, Heidegger ressalta o ser do homem como ser-aí, com o seu caráter de abertura, clareira na qual irão se manifestar os entes. Nessa direção, a ênfase recai na condição ontológica de existir, enquanto poder-ser, modo de existir distinto da compreensão fundada em propriedades já dadas enquanto potencialidades a serem desenvolvidas.

A Analítica Existencial, inicialmente, revela a noção de "ser-nomundo", a qual diz respeito aos vários modos do Dasein no mundo. Mundo, nesse sentido, não é visto como um espaço no qual se encontra tudo o que existe; é um existencial, trama de significados e sentidos tecida pelos homens; morada na qual as coisas podem aparecer e se apresentam junto com os outros entes para a abertura ao sentido. Heidegger adverte a nossa tendência em tomar o homem e o mundo como duas entidades separadas, devido a tradição metafísica. Por outro lado, situa a condição homemmundo como co-originária, não sendo possível pensar em homem sem mundo.

Em "Ser e tempo", Heidegger (2012) destina três capítulos para apresentar como se desdobra a presença do homem junto às coisas circundantes e aos seus semelhantes. Nessa direção, afirma que o modo de ser do cotidiano - inautêntico - possibilita o afastamento de si-mesmo; em meio às exigências do público, vive mergulhado na massificação do mundo. Ao mesmo tempo, pode caminhar para um modo de ser autêntico, afastando-se do impessoal e acolhendo o apelo do ser, assumindo sua própria estranheza diante do nada e abrindo-se para outro modo de estar no mundo com os outros e as coisas.

Com vistas a um entendimento a respeito do sentido atribuído por Heidegger às condições autêntica e inautêntica, é preciso desvinculá-las de conotações morais, valorativas ou teológicas, pois ambas dizem de duas possibilidades fundamentais, nas quais se encontra o Dasein. A partir de tal perspectiva, não é viável tomar a inautenticidade como negligência ou fraqueza do homem, bem como a condição autêntica da ek-sistência enquanto beatitude, moralmente melhor.

Interessa-nos situar a compreensão existencial de Heidegger a respeito do Dasein homem a fim de utilizá-la como preparação para as considerações posteriores. Nesta trilha compreensiva, almejando desenvolver as discussões propostas como objetivo de estudo do presente artigo, a seguir, serão tecidas algumas rápidas considerações sobre o "Heidegger tardio", com vistas a ajudar a retomar a pergunta sobre o sentido do ser.

Cabe ressaltar que, essa atitude possibilitou o desprendimento do modo metafísico vigente de pensar e o levou a interpretar o tempo como possível horizonte para toda e qualquer compreensão do ser. Para Barreto (2013, p.41, aspas da autora):

Uma compreensão do contemporâneo a partir do diálogo com o pensamento de Martin Heidegger - Ellen Fernanda Gomes da Silva; Carmem L. B T. Barreto 
tal mudança paradigmática só é possível orientando os passos do pensamento em direção ao caminho que conduza a superação da metafísica [....] não como simples projeto de nossa vontade consciente, já que se trata de um 'destino' aqui compreendido como aquilo que o âmbito da verdade do ser nos dispensa.

\section{Heidegger e a técnica moderna}

Caminhando na trilha do pensamento aberto por Heidegger, chega-se ao fenômeno da técnica, na tentativa de refletir sobre suas consequências no momento atual. Tal reflexão é realizada ciente de que não era proposta de Heidegger investir contra a técnica, mas apontar para a falta de reflexão crítica a seu respeito e aos usos decorrentes. Inicialmente, segundo Critelli (2002), importa situar a técnica enquanto foco da crítica presente no pensamento heideggeriano, a qual expressa um modo-de-ser característico da ocidentalidade. É, pois, uma orientação de conduta aplicada a cada gesto e em relação a tudo.

Segundo Duarte (2010), o fenômeno da técnica começou a ser discutido por Heidegger a partir de 1940. A sua principal análise se encontra no ensaio "A questão da técnica", publicado, originalmente, em 1954. Fazse oportuno mencionar que tal pensamento floresceu no contexto da Segunda Guerra Mundial.

Ao buscar compreender criticamente a técnica Heidegger (2001) discorre acerca da tendência de compreendermos a técnica, simplesmente, como um meio para um fim ou enquanto atividade do homem. Não que ambas concepções - de determinação instrumental e antropológica da técnica - não devam ser consideradas, mas, ao tomá-las como única verdade, obstruímos o caminho para o sentido originário do que se chamou de "essência da técnica".

Para Heidegger (2001), na era da técnica o homem moderno entende a si mesmo e ao mundo na razão direta da sua capacidade de dominar e manipular o mundo e os outros. Nessa perspectiva, toda a natureza é posta como fundo de reserva a ser explorado, armazenado, transformado e distribuído. O próprio homem é visto como algo a ser disposto, possível de ser calculado. Nesta lógica da contemporaneidade, um desvelamento que se apresenta é a utilidade, ou seja, nada pode existir sem uma finalidade.

É nesse modo de compreensão do real, em que tudo é reduzido a leis de causa e efeito, que a temática da contemporaneidade encontra morada. $\mathrm{Na}$ tentativa de ampliar essa discussão, cabe mencionar que, enquanto história do ser, um traço que marca a Modernidade se refere a visão de homem representável, que reúne tudo em torno de si, fundamento inquestionável da verdade. Os sinais dos tempos revelam a inclinação técnica de tentar definir, dominar o mundo e todas as coisas que nele se

Uma compreensão do contemporâneo a partir do diálogo com o pensamento de Martin Heidegger - Ellen Fernanda Gomes da Silva; Carmem L. B T. Barreto 
apresentam, inclusive o homem - tomando como sujeito objetivado. Está em Aristóteles e Platão o princípio desta empreitada, quando os mesmos buscaram demarcar precisamente o existente e, posteriormente, tal intento se alastrou para o agir humano. Esta delimitação do ser, na medida da razão calculadora, foi reafirmada e ampliada na Idade Moderna com Descartes (CRITELLI, 2002).

Segundo Heidegger (2009), a ideia grega de ocultamento e desvelamento do humano, guardando uma certa ambiguidade, desloca-se para a representação. A partir de tal perspectiva, o método, enquanto caminho para chegar à verdade, traz a determinação da segurança (pois é representação clara do objeto investigado) e da veracidade (como certeza calculada). Desta maneira então, por meio de tal entificação do ser, a questão sobre o que seja o ser mesmo, em sua diferença ontológica, permanece esquecida. Deste modo, a técnica se constitui como esvaziamento do ser e, portanto, de todo mistério. Dá-se uma condição de desencantamento, na medida em que não há meditação sobre o sentido das coisas. A técnica, nesse contexto, revela-se niilizante.

Ampliando tal reflexão, a seguir, Michelazzo (2000) será tomado como referência, visto que tal autor parte da análise heideggeriana a respeito da essência da técnica. Ao problematizar a devastação da terra, a massificação do homem e a fuga dos Deuses como fenômenos que surgiram desde a Modernidade, Michelazzo oferece possibilidades para caracterizar a técnica e o consequente obscurecimento do mundo.

O primeiro deles - a devastação da Terra - vem sendo empreendido com velocidade desde a Revolução Industrial com o propósito de alimentar o mecanismo da reprodução e do consumo da sociedade moderna. Tal ação não conhece limites e fronteiras; sem descanso no seu manuseio, por não repor suas energias, a terra torna-se estéril. Cabe ressaltar que, na condição de "senhor da terra", o homem, ao passo que consegue assenhorar-se dos recursos tecnológicos, alimenta a ilusão de controle sobre o devir; que, simultaneamente, lhe escapa.

Seguindo o fluxo da voracidade, o homem também é tomado como fundo de reserva, "o melhor dos recursos para a produção, a melhor das demandas para o consumo" (MICHELAZZO, 2000, p.105). Em meio a massificação, o homem é mais um, um ser-em-comum, que frequenta os mesmos lugares, tem a mesma opinião e se veste do mesmo modo que os outros.

Nessa linha de pensamento, Vattimo (1996) situa que a instrumentalização do mundo pode ser percebida na ditadura da publicidade. O ser-público tem tudo à amostra, não há mistério, há somente o "aindanão" descoberto ou explicado pela ciência. Conquanto, o que se conhece da coisa é apenas o seu caráter funcional, na sua instrumentalidade. Nesse sentido, a reflexão ao que se denomina por "a questão da técnica" é 
fundamentalmente uma crítica à representação, a qual reflete o esvaziamento total do ser em um mundo convertido em imagem.

A continuidade de questionamentos sobre o obscurecimento do mundo é também marcada por outro traço: a fuga dos Deuses. É a época do afastamento do esplendor da divindade, na qual nenhum Deus reúne os homens e as coisas em torno de si. Com este terceiro fenômeno o mundo perde ainda mais o fundamento que dá sentido as coisas. Para suportar esse vazio, geralmente, os homens preenchem suas vidas com coisas e pessoas, as quais ofertem algum tipo de sentido, seja ele efêmero ou irreal.

Seguindo o fio condutor da conversação, no texto de Heidegger (1959) "Serenidade", podemos compreender que a preocupação maior de Heidegger diz respeito a estarmos vivenciando o crescimento e a transformação da técnica sem nos darmos conta da dimensão de tal fenômeno, bem como de suas ressonâncias. Neste entorno, ao caminharmos indiferentes à reflexão, o sentido do mundo técnico se oculta.

Nas palavras de Duarte (2010, p.53):

[...] o mundo tecnocientífico nos confronta com o perigo da perda de sentido, de compreensão, de pensamento, isto é, nos ameaça com a perda das capacidades genuinamente humanas. Estas vêm sendo cada vez mais rapidamente substituídas pela estrita capacidade de raciocinar e calcular consequências, podendo, perfeitamente, ser substituídas por computadores. Heidegger denominou esse processo, de maneira muito apta, o predomínio moderno do pensamento calculador sobre a meditação serena do sentido.

Conforme Heidegger (2001, p.11), enquanto estivermos em sintonia com o pensamento vigente a respeito da técnica, ficaremos presos, sem liberdade, "tanto na sua afirmação quanto na sua negação apaixonada". Em outros termos, Heidegger nos convida a "superação da nossa atitude oscilante entre o louvor das maravilhas da moderna tecnologia e o temor do desastre tecnológico mais sombrio" (DUARTE, 2010, p.122). Com base nessas considerações, uma postura de questionamento solicita perguntar o que a técnica "é". Para chegarmos à essência ou ao menos à sua vizinhança, cabe-nos o empenho de um exercício de reflexivo.

Acompanhando este modo de pensar e retomando o sentido original do termo técnica - do grego techné - Heidegger (2012) traz a ideia de um fazer artesanal; permitir que algo possa vir à luz, um modo de instauração da verdade em seu sentido originário (alethéia). Nessa interpretação, o desocultamento do ente na sua verdade, pensado na téchne pelos gregos, nunca é uma atividade do homem, mas um produzir que deixa de antemão que o ente chegue à presença de acordo com o seu aspecto.

Afinados com tal compreensão, tomamos distância do controle, do desejo de tudo dominar, característicos do nosso tempo. No rompimento das amarras que supostamente nos determinam, abrimos espaço para uma livre

Uma compreensão do contemporâneo a partir do diálogo com o pensamento de Martin Heidegger - Ellen Fernanda Gomes da Silva; Carmem L. B T. Barreto 
correspondência com a técnica, na qual os sentidos podem vir à lume. Esse confronto com o espírito do tempo, pode possibilitar espaços de criação de outras referências e possibilidades de ser, que não estão na fixidez e no controle, mas sim no mistério e no estar aberto para o novo.

\section{Considerações finais}

"A ética originária de Heidegger pede o desapego a todo o agir causal. Trata-se de substituir a pergunta que, na época da metafísica, era a única urgente: que devemos fazer? pela interrogação: como temos que pensar?" (LOPARIC)

No horizonte das compreensões aqui dialogadas, o homem revela-se, na maior parte das vezes, adequando-se a engrenagem da vida cotidiana, a qual, provoca-lhe incerteza e familiaridade, frente ao conforto e segurança do nivelamento social. O que tentamos interrogar é o diapasão totalitário que circunscreve e marca a contemporaneidade como uma forma da verdade, a saber, a razão tecnológica.

Na contemporaneidade, o projeto do homem é de um ideal de existência na busca da satisfação das sensações, de um novo contínuo, alicerçado no imediato. Neste sentido, o clamor da angústia vem trazer a "estranheza" do homem contemporâneo, a sinalização da finitude - nossa condição mais própria. Ao apontar a dimensão trágica da vida, também revela a dimensão de abertura do ser do homem, a condição de estar em jogo no tempo.

Seguindo os caminhos de Heidegger, é preciso "despertar" do modo de pensar enraizado na razão instrumental, o qual potencializa o perigo de cairmos nas malhas do tecido tecnológico e pode tornar dependentes de si às diversas formas de organização social, culminando numa tradição marcada pelo uso, controle e ofuscamento pelas luzes da contemporaneidade.

Na dimensão propriamente humana podemos refletir, com Heidegger (2012), como o modo usual do homem existir apresenta-se atrelado aos esquemas da "grande massa", caracterizando o mundo do "se", do "a gente", do falatório curioso, porém não revelador da compreensão e apropriação da experiência. Cada vez mais o homem vive o tempo da vivência, não elaborando suas experiências, dimensão que poderia encaminha-lo para outro modo de existir - apropriando-se e relacionando-se a possibilidade de retirar-se do anonimato do "se".

Nessa linha de reflexão, o pensar não está separado do agir, ele age enquanto se exerce como pensar. Tal compreensão exclui a possibilidade de uma ação decorrente da aplicação do pensamento e aponta para um pensar e um agir em sentido "elevado", implicado não na separação da ação pela transposição de formas de aplicação. Em tal perspectiva, o pensar é ele 
próprio ético, no sentido não prescritivo de modo de ser (GIACOIA, 2013). Deste modo, pensar a essência da técnica na contemporaneidade é responder a um apelo libertador, restituindo-se a correspondência rompida entre homem e ser.

\section{Referências}

AGAMBEN, G. O que é o contemporâneo? e outros ensaios. Chapecó: Argos, 2009.

BARRETO, C. L. B. T. Reflexões para pensar a ação clínica a partir do pensamento de Heidegger: da ontologia fundamental à questão da técnica. In: BARRETO, C. L. B. T.;

MORATO, H. T. P.; CALDAS, M. T. Prática psicológica na perspectiva fenomenológica. Curitiba: Juruá, 2013, pp. 27-50.

BAUMAN, Z. Vidas em fragmento: sobre ética pós-moderna. Rio de Janeiro: Zahar, 2011.

BENJAMIN, W. Origem do drama barroco alemão. São Paulo: Brasiliense, 1984.

CRITELLI, M. D. Martin Heidegger e a essência da técnica. Margem, n. 16, pp. 83-89, dez. 2002.

DUARTE, A. Vidas em risco: crítica do presente em Heidegger, Arendt e Foucault. Rio de Janeiro: Forense Universitária/GEN, 2010.

GIACOIA, J. O. Heidegger urgente: introdução a um novo pensar. São

Paulo:

Três estrelas, 2013.

HEIDEGGER, M. Ser e tempo (7ª ed). Petrópolis: Vozes, 2012.

HEIDEGGER, M. Todos nós... Ninguém: um enfoque fenomenológico do social. São Paulo: Moraes, 1981.

HEIDEGGER, M. Serenidade. Lisboa: Instituto Piaget, 1959.

MICHELAZZO, J. C. Corpo e tempo. In: CASTRO, D. S. P. DE;

PICCINO, J. D.; JOSGRILBERG, R. DE S.; GOTO, T. A. Corpo e

Existência. São Paulo: Metodista, 2004, pp. 105-122.

\section{Contribuição dos autores:}

Ellen Fernanda Gomes da Silva, Carmem L. B T. Barreto contribuíram com a discussão, problematização, revisão e redação do artigo. A versão final do texto foi aprovado por ambos os autores 